\title{
Utilisation of joint movement range in arboreal primates compared with human subjects: an evolutionary frame for primary osteoarthritis
}

\author{
Colin J Alexander
}

\begin{abstract}
Objective-To determine whether an arboreal lifestyle required full use of movement ranges underutilised in nine joint groups in humans, because underutilisation of available movement range may be associated with susceptibility to primary osteoarthritis.

Methods-Utilisation of the nine joint groups was studied in two species of primate exercising in a simulated arboreal environment, using 'focal animal' observation techniques supplemented by telephoto photography and by review of archival material from other sources. Fifteen apes were observed over a total observation period of 20.2 man-hours and 152 films were analysed for utilisation of movement range.

Results-With one exception, all the movement ranges reported to be underutilised in humans were fully utilised by the apes in climbing activities. The exception, metacarpophalangeal extension, was an essential component of the chimpanzee ground progression mode of knuckle walking.

Conclusions-The underused movement range in several human joints is explicable as residual capacity from a semiarboreal lifestyle. If the correlation with primary osteoarthritis is confirmed, it suggests that the disease may reflect a disparity between inherited capacity and current need. The significance of the result lies in its implication that primary osteoarthritis may be preventable.
\end{abstract}

(Ann Rheum Dis 1994; 53: 720-725)

The 'incomplete use' theory for primary osteoarthritis, based originally on histological and epidemiological evidence, ${ }^{1-4}$ has received support in more recent years from behavioural studies reporting an apparent association between utilisation of available arc in individual joints and their susceptibility to primary osteoarthritis. ${ }^{5-7}$ The degree of underutilisation found in some joints is substantial, and poses the question of why the human species should be endowed with ranges of movement apparently in excess of need.
In evolutionary terms, the only likely explanation for excess capacity is a relatively sudden change in behaviour which has happened too recently for the surplus to be bred out by selection. There have been two behavioural changes during human evolution which fit these requirements: abandonment of an arboreal lifestyle approximately 6 million years ago, ${ }^{89}$ and adoption of the erect posture, which is known to have been complete 3.75 million years ago. ${ }^{10}{ }^{11}$ If these changes resulted in a reduced need for movement range in some joints, then the incomplete use theory of primary osteoarthritis generates two predictions against which it can be tested: arboreal primates are free from primary osteoarthritis, and arboreal activities require full use of the joints found to be underused in humans. This study investigated the latter prediction.

In human behavioural studies, ${ }^{5-7}$ underutilisation of available arc was identified in the following joint groups: cervical spine (extension only); glenohumeral (external rotation); glenohumeral and acromioclavicular (abduction); metatarsophalangeal (flexion); knee (flexion); hip (flexion); distal interphalangeal (flexion); first carpometacarpal (full abduction). Both the initial observational ${ }^{5}$ and a later goniometric ${ }^{12}$ study also showed underuse of extension in the metacarpophalangeal (MCP) joint. In the normal controls for the latter study the mean extension range was $59^{\circ}$, but in the 140 observations of these two studies extension past the zero axis was recorded only twice, and did not exceed $10^{\circ}$. There is thus considerable underuse of this movement in humans.

The objective was to investigate the manner in which these joints are used in arboreal primates, and in particular to determine if this lifestyle requires regular use of the arcs found to be underutilised in human subjects.

\section{Subjects and methods}

The primate genetically closest to humans is the chimpanzee, with a genetic difference, estimated from DNA and protein analysis, of less than $2 \%{ }^{811}$ This species (Pan troglodytes) is represented in the Auckland Zoo by a main group of six individuals (four adult and two juvenile) and a separate subgroup of three adults. Data were acquired using 'focal animal' 
observation techniques ${ }^{13}$ in both groups. The main group were observed while the chimpanzees were on a simulated arboreal climbing frame in an outdoor enclosure. The observation distance for the main group was approximately 11 metres and direct observation was supplemented by use of $8 \times 50$ binoculars and by photography using telephoto lenses. Two different observation techniques were used.

In the first study attention was restricted to the chimpanzees' use of the hands while they were climbing or descending, the observations being recorded by two observers using two telephoto cameras over a period of three hours. The focal animal in this study was any animal actively engaged in climbing activity on the frame. During this session 91 films were taken and produced 84 useable films of hand positions. These were classified as 'full power', 'partial power', 'precision' or 'hook' grips, using definitions of hand position previously described. ${ }^{12}$ In the second study the chimpanzees were monitored while on the climbing frame, to record the use of the other limb joints and the cervical spine. Attention was directed to those movement ranges found to the underutilised in humans. The positions used by the primates were noted and examples recorded photographically. The observation period for this phase totalled $11 \cdot 2$ hours spread over five sessions. The data base was extended by further close range observation of the three other chimpanzees in a smaller, tree-equipped enclosure, and of six orang-utans (Pongo) on their own open air climbing structure. The observations were supplemented by examination of the primate section of the zoo photographic library, the photographic records of a University primate research project, and the primate photographic files of a local newspaper. The data base from this section of the study included 61 photographs.

\section{Results}

The following observations were made on the joints monitored:

Metatarsophalangeal joints Abduction of the great toe in climbing chimpanzees is well known and was regularly observed. Flexion of all the toes and plantar flexion of the foot, movements which are restricted in shod humans, occurred regularly in both primate species (fig 1).

Hips and knees At both these joints the flexion ranges underused by humans were fully utilised by the primates while squatting and ground sitting (fig 2). Both joints were extended in the erect bipedal and suspended positions.

Cervical spine Full extension of the neck, rarely observed in the human behavioural studies, ${ }^{5}$ was commonplace in the primates (fig 2 ). Both species regularly looked upward before starting to climb and while climbing, with maximal cervical extension occurring when the initial posture was quadrupedal.

Shoulder girdle External rotation of the glenohumeral joint was seldom seen when the

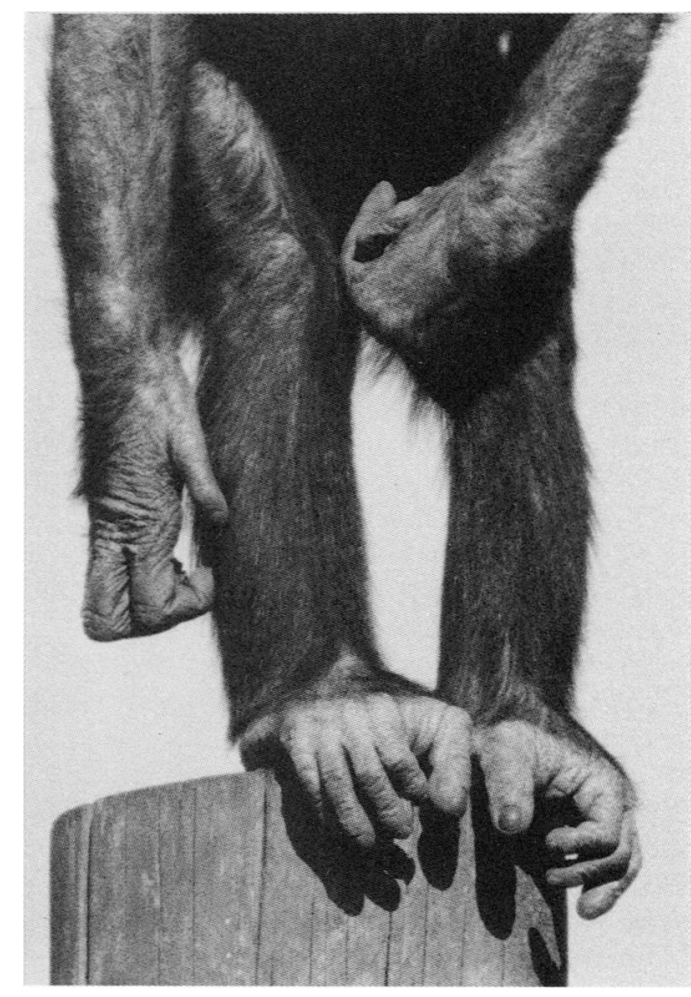

Figure 1 Chimpanzee standing bipedally, with flexion of the metatarsophalangeal and proximal interphalangeal joints. The film also shows slight MCP extension of the right hand.

primates were on the ground but was common during suspensory activities in both species. The full abduction or flexion of the shoulder girdle required for complete excursion of the acromioclavicular joint ${ }^{14}{ }^{15}$ was also a necessary component of arboreal locomotion (fig 3). It was one of the most frequently used positions, contrasting with its relative rarity in human subjects. ${ }^{5}$

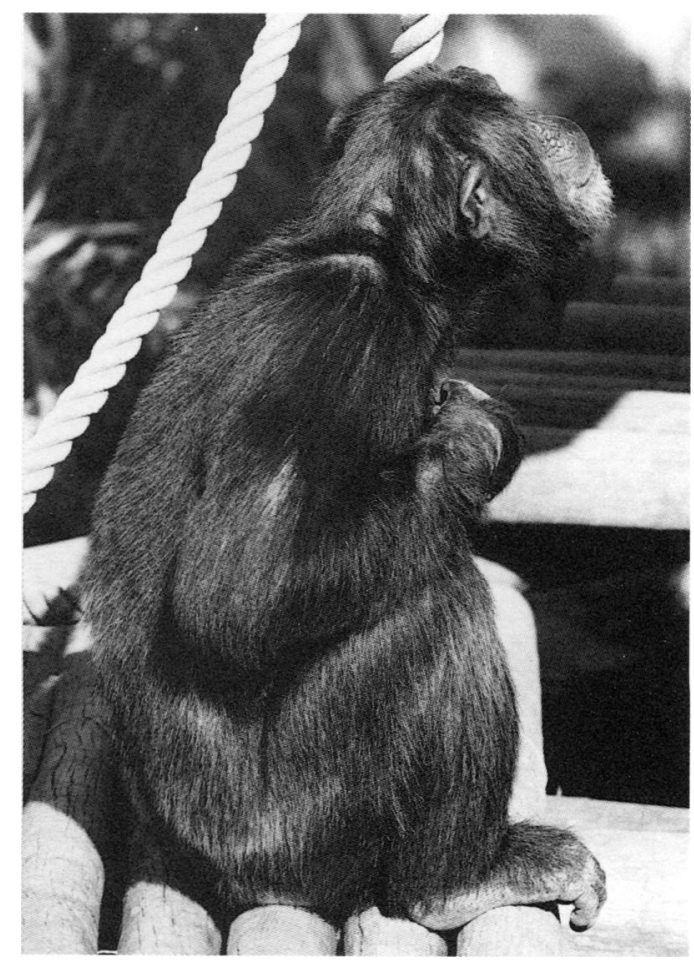

Figure 2 Chimpanzee ground sitting, hips and knees flexed, cervical spine extended. 


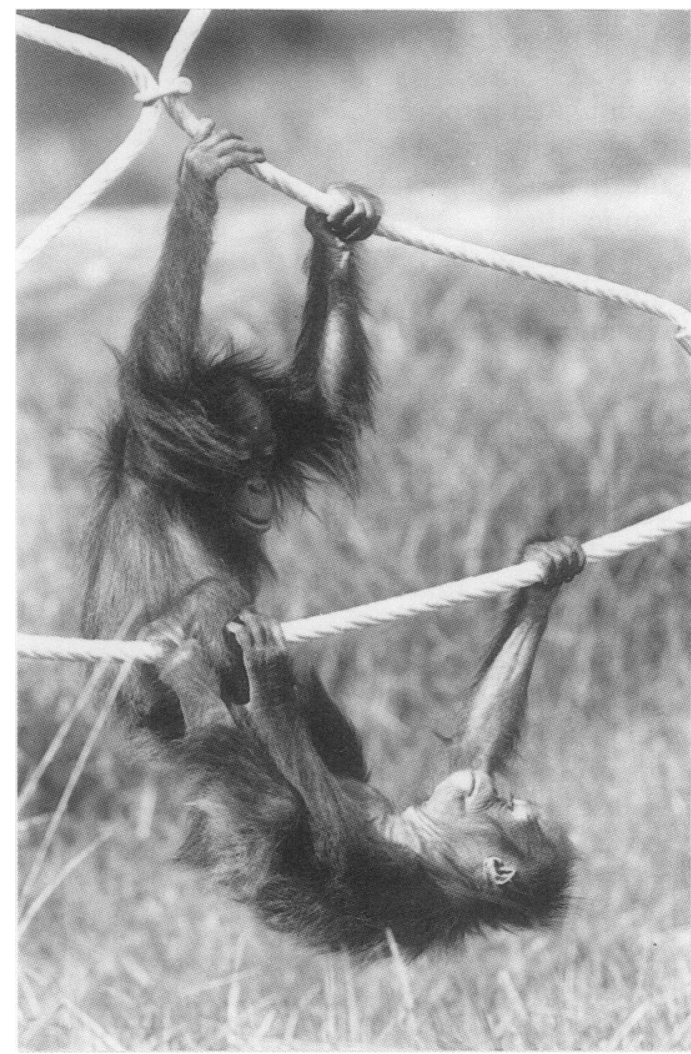

Figure 3 Orang-utans in suspended mode. The lower shows supination of the right elbow; the upper, abduction/ flexion of the right shoulder girdle and MCP and proximal interphalangeal flexion in the left hand.

Elbows In the investigation of human excursion ranges, ${ }^{5}$ elbow flexion was found to be fully utilised, and it had not been intended to study this joint in the chimpanzees. Observation of supination in the primates prompted interest in this movement, however.

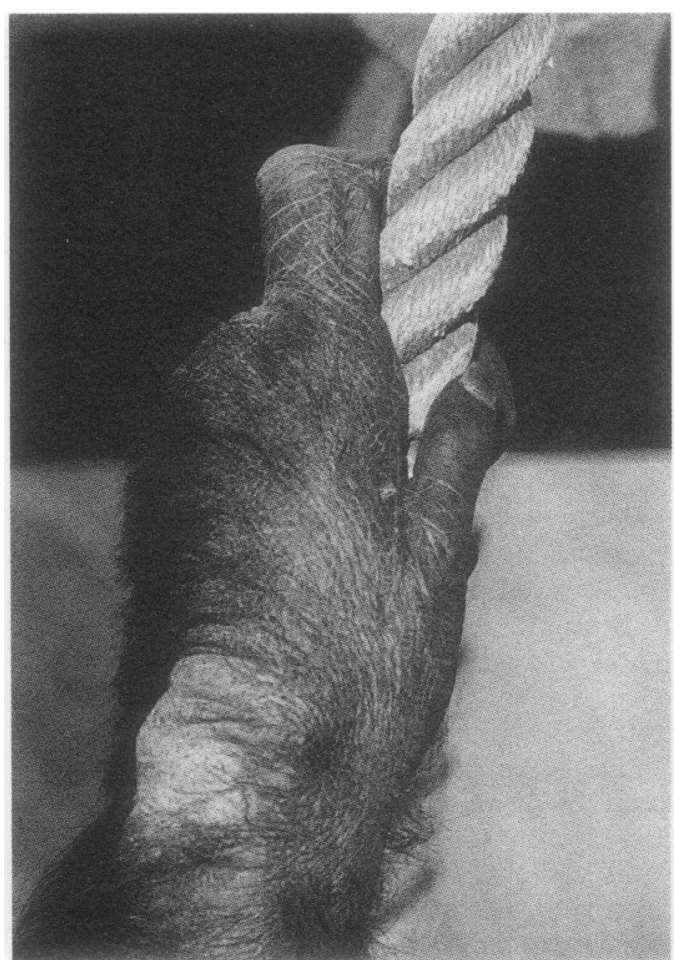

Figure 4 Chimpanzee descending rope using a partial power grip, thumb adducted in line with the object grasped.

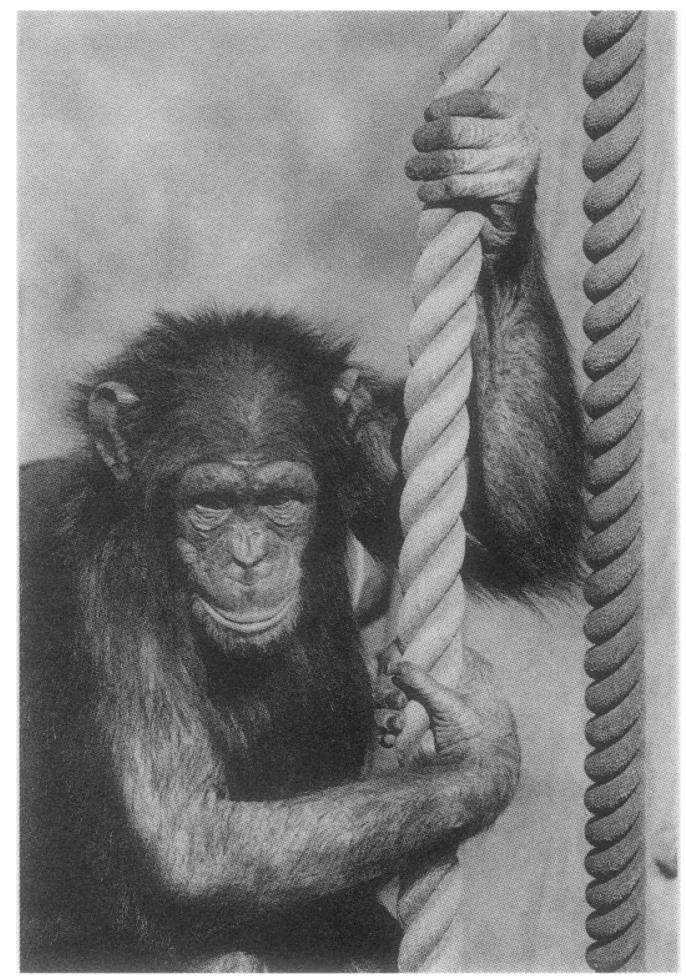

Figure 5 Chimpanzee preparing to climb, adopting a full power grip, thumb across the object grasped in palmar abduction.

It was commonly observed in the orang-utans while they were brachiating (fig 3), and occurred more rarely in chimpanzees during suspended phases. This primate requirement for full supination has long been known to zoologists, ${ }^{16}$ but the utilisation of supination by humans has not been studied.

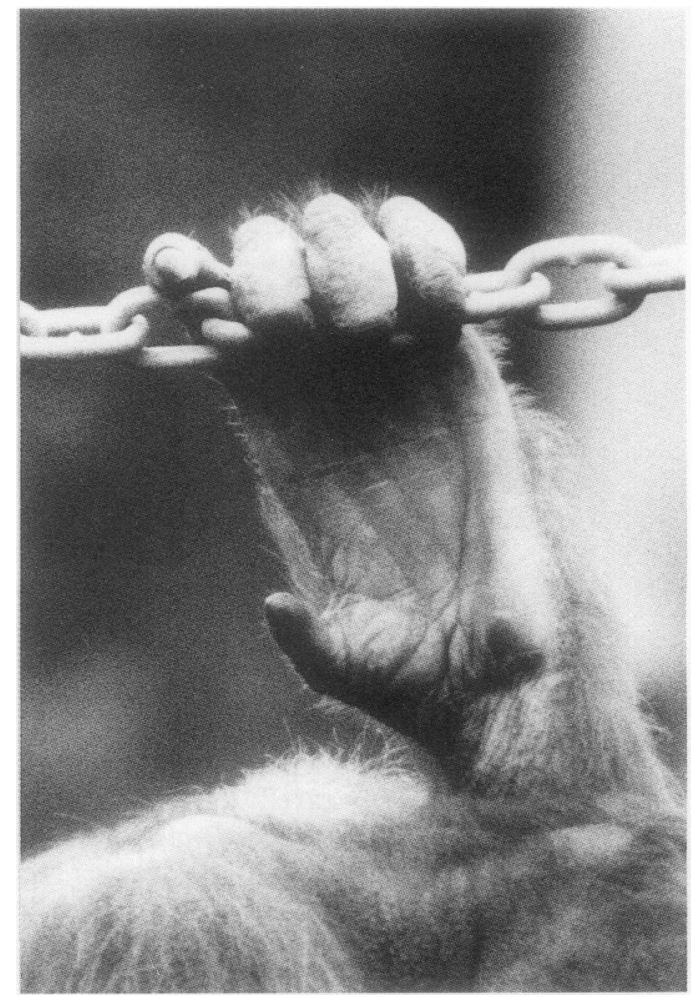

Figure 6 Orang-utan hook grip, bearing surface proximal interphalangeal joint, thumb functionless. 


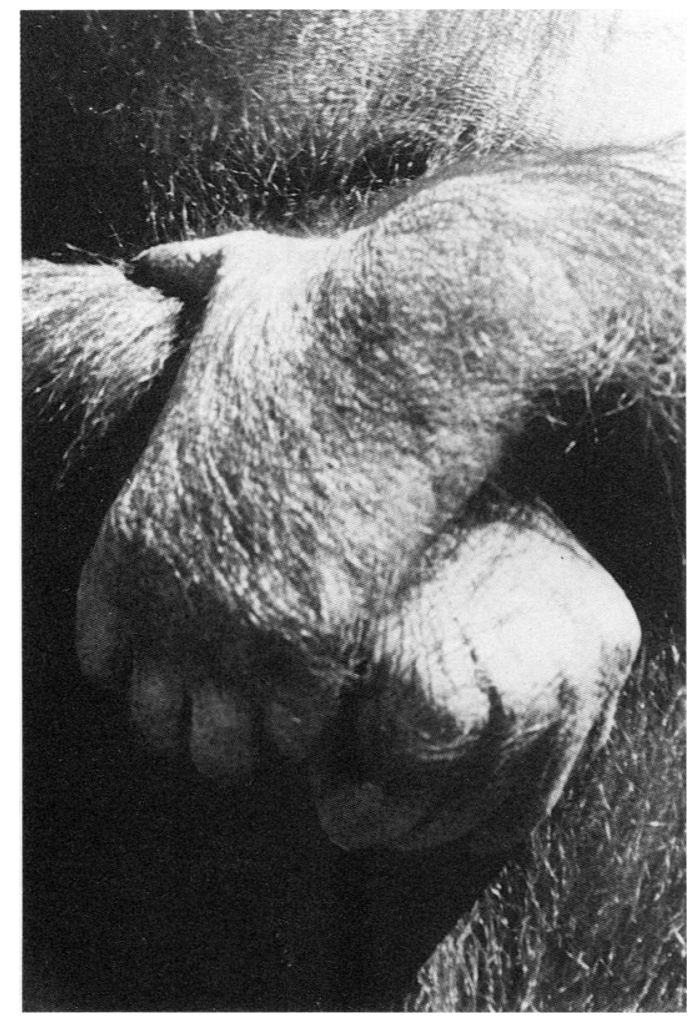

Figure 7 Orang-utan partial power grip, thumb in radial abduction.

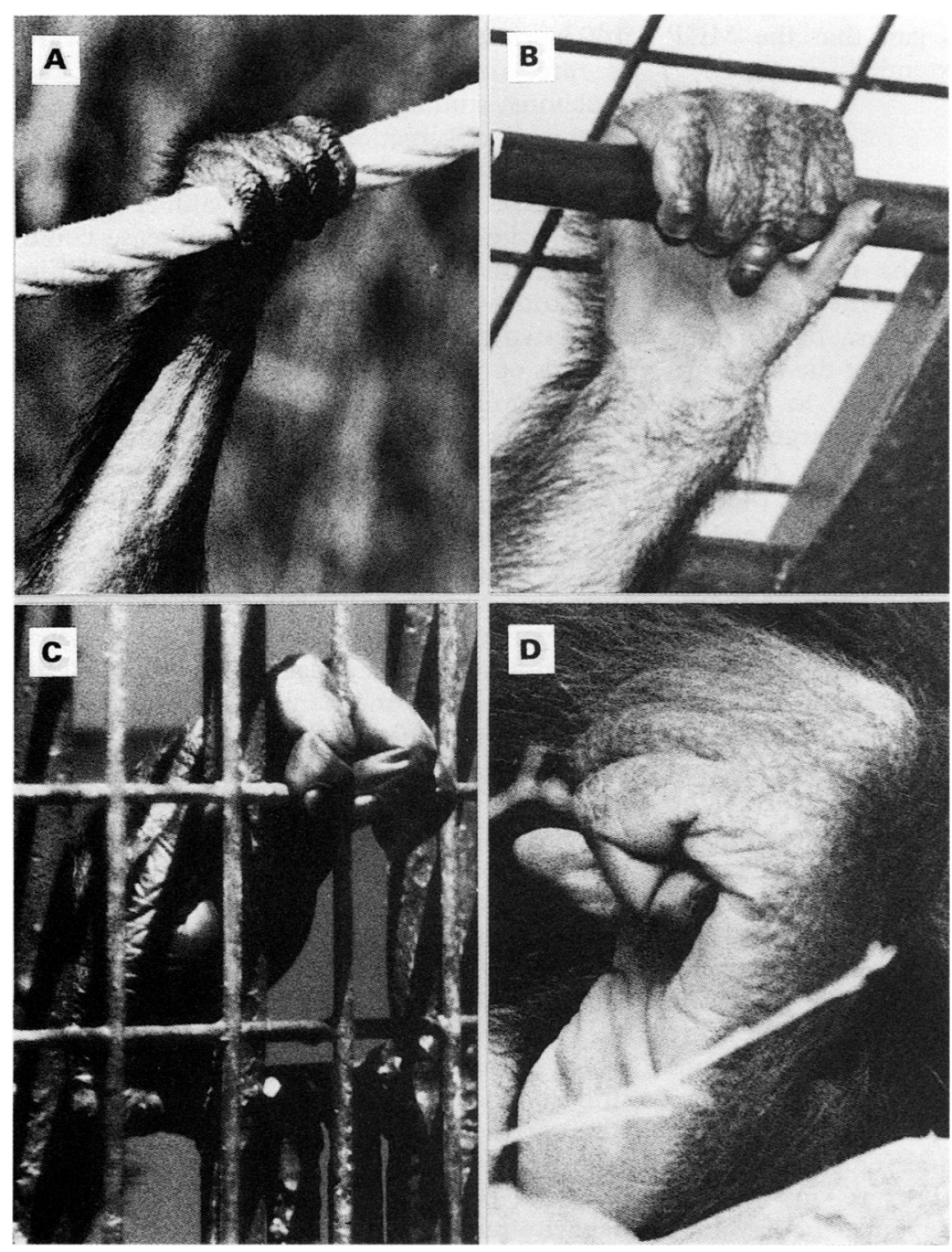

Figure 8 Chimpanzee grips while suspended showing flexion of the $M C P(A, B, D)$ and proximal $(A-D)$ and distal $(B-D)$ interphalangeal joints.
Hand grip use Utilisation of the hand positions observed in the chimpanzees differed from that found in humans, with climbing and suspensory activities making much more use of the power and hook grips. Of the 48 films in which visualisation of the hand was adequate to allow identification of the grip used, the hand position was categorised as partial power in 18 (fig 4), full power in nine (fig 5), and hook in 10 (fig 6), using the definitions previously reported. ${ }^{12}$ In 11 films the position was intermediate between full and partial power. The usual grip when suspended was the hook grip. The precision grip so much utilised by humans was not observed during the climbing phases but was extensively used at other times, for grooming, feeding, and investigating the surroundings. Fifteen films showing chimpanzee precision grips were available from the University primate project and three different categories could be identified: lateral pinch between the thumb and the radial aspect of the index or first metacarpal (seven), lateral pinch between the index and middle fingers (five), and tip pinch between thumb and index (three).

Thumb The shorter thumb of the chimpanzee reduced its importance in the power grips compared with humans. Unless the object grasped is small, the chimpanzee thumb is too short to lock the fingers and, as a consequence, the distinction between full and partial power was less clear cut in the primates. When the object was small, however, the thumb was seen to be used as in humans, in palmar abduction and at or near right angles to the object grasped (fig 5). When the chimpanzees were holding wide objects such as the beams of the frame the thumb was in radial abduction (fig 7). In partial power grips it was adducted or intermediate between these extremes (fig 4). In the hook position in both species, and particularly in the orang-utan, the thumb was in neutral position and largely functionless (fig 6).

Interphalangeal joints The main difference in hand use between human and chimpanzee was the marked flexion of the interphalangeal joints in the high power hook grip used for suspension. As has been observed in previous studies, ${ }^{17} 18$ the bearing surface in the hook grip photographs was the middle or proximal phalanx or the proximal interphalangeal joint (figs $3,6,8$ ). In the first case substantial flexion of the distal interphalangeal joints is needed to secure the grip and was regularly observed. In both grips near maximum flexion was seen at the proximal interphalangeal joint (figs 3, 8).

Metacarpophalangeal joint In this joint, the prediction that all the underutilised ranges would be needed for climbing was not borne out. In the power grips used by chimpanzees for climbing, full MCP flexion was seen (figs 3,8 ), but extension was identified only once in the 84 hand films (fig 1). This was surprising, as chimpanzees are known to have a substantial MCP extension range. ${ }^{18}$ The discrepancy was resolved when the chimpanzees were observed during quadrupedal gait phases: the normal technique used for ground walking by chim- 


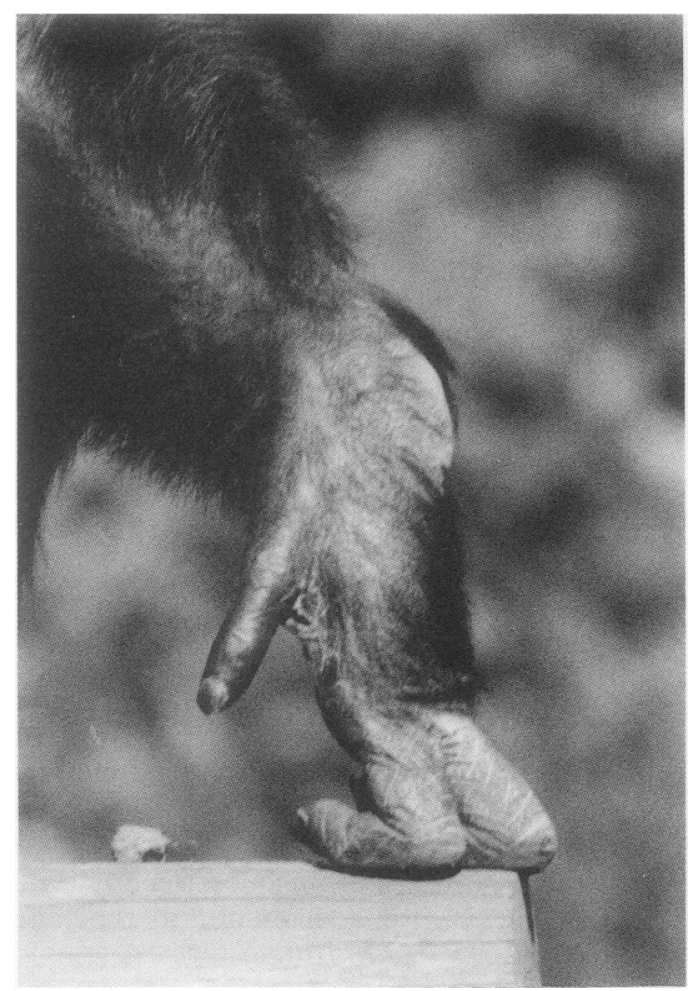

Figure 9 Chimpanzee knuckle walking, showing marked extension of the MCP joints.

panzees and gorillas is knuckle walking, and it is a requirement of this gait that the MCP joints are forcibly hyperextended ${ }^{18-20}$ (fig 9).

\section{Discussion}

In every case in which an underused segment of arc has been identified in humans, the primates studied utilised the idle segments, either during arboreal activities or when knuckle walking. There has been some difference of opinion concerning the existence of a knuckle walking phase in human evolution, 82122 but retention of a large unused MCP extension range and the common presence of knuckle pads in modern humans ${ }^{23} 24$ support arguments for such a phase. The evidence is consistent with the conclusion that the movement ranges in the joints of modern humans reflect, not current need, but the imperatives of an arboreal past. Their persistence is not surprising as there has been no survival value in their obliteration.

The underutilisation presumably started when the prehuman stock diverged from the chimpanzee line and adopted an initially quadrupedal savannah lifestyle. ${ }^{825}$ Leaving the trees reduced the need for full shoulder abduction/flexion, cervical extension and the power and hook grips. Arboreal primates are critically dependent on a powerful hook grip, ${ }^{17}{ }^{26}$ and this grip depends for its security on the ability to lock the fingers around branches of different calibre, the position of the fingers varying according to the size of the branch and the force needed. This need for full interphalangeal flexion is rare in modern humans. In the cervical spine the reduced extension required for ground foraging was then compounded by adoption of the erect posture, which further reduces the need for extension. This second change also obliterated the need for extension of the MCP joints. Two subsequent changes in lifestyle further reduce the ranges required: adoption of footwear effectively prevents flexion of the foot and toes, and the recent adoption of sitting in chairs has substantially reduced the flexion profile of hip and knee. ${ }^{4627}$ There is epidemiological evidence of a smaller prevalence of osteoarthritis in the great toes and hips (but apparently not the knees) of communities which avoid these two practices. ${ }^{48-32}$

The observation that arboreal primates use larger ranges of joint movement than humans does not by itself justify the conclusion that the underuse may be related to the development of primary osteoarthritis. For this to be tenable it would be necessary to confirm the complementary first prediction, that primary osteoarthritis should be rare in arboreal primates. There is some evidence to support this contention. Jurmain ${ }^{33}$ examined the skeletons of 17 Gombe chimpanzees, using direct inspection and radiography. The regions examined included the main limb joints, the small joints of the hands and feet, and the spine, and Jurmain reported that osteoarthritis was extremely rare in these joints, despite evidence of considerable trauma. Rothschild and Woods, ${ }^{34}$ in a study of the skeletons of 1403 primates, also reported that the disease is rare, occurring in less than $1 \%$ of the skeletons studied. They made the possibly important observation that the disease was six times as common in primates confined in zoos as in those ranging free in the wild. A possible explanation for the rarity of the disease could be a relatively short life span, but Goodall in her study of 160 chimpanzees over 30 years estimated a life span of 45 years, and quoted records of two individuals aged 52 and $54 .{ }^{35} \mathrm{As}$ Heine $^{36}$ found significant osteoarthritis in and below the fifth decade in his postmortem material, it seems unlikely that too short a life span can explain the negligible incidence in arboreal primates.

The proposition that primary osteoarthritis may be a maladaptive disease arising from a discrepancy between inherited design and current function has already been advanced by Hutton. ${ }^{37}$ The mechanism postulated by Hutton-mechanical overload-showed only partial correlation with regional prevalence. If incomplete use is substituted for overload the correlation with local prevalence seems stronger but is still not perfect. There are three discrepant joint groups in which underuse is not associated with a high prevalence of osteoarthritis-MCP, lateral metatarsophalangeal, and glenohumeral-but in each case there are local anatomical differences which partially decouple joint loading from full utilisation. These differences have been discussed elsewhere, ${ }^{5}$ and may explain the relative sparing at these sites.

The hypothesis which emerges from these behavioural studies, that primary osteoarthritis may be a manifestation of the "law of use or lose' is not new. The studies do no more than 
provide evidence of a possible evolutionary basis as ultimate cause and a bifactorial rationale as proximate cause, for the underuse hypothesis of Harrison et al ${ }^{1}$ and others. ${ }^{3427} \mathrm{It}$ is clear that the hypothesis applies only to the primary form of the disease, and it does not explain the location of changes within the joint, which seems to be a function of focal loading irrespective of the cause of the degenerative change.

The hypothesis has two implications which diverge to some extent from current views. First, that notwithstanding the similarity of their end stage histology, primary and secondary osteoarthritis arise from different mechanisms. Second, that primary osteoarthritis is theoretically a preventable disease. Whether this is true in practice is a different matter, but it is a sufficient goal to justify further research.

I wish to thank Jo Knight and Peter West of the Auckland Zoological Gardens for their cooperation and helpfulness in setting up the observation sessions; Professor Richard Bellamy of the school of biological sciences, University of Auckland, for his assistance, Ian MacDonald of the same department for his considerable photographic expertise in obtaining most of the photoraphs illustrated, and Mark Shelley of the an photographs illustrated, and department for photographic reproduction. I must also thank Beverley Butler, whose primate study provided most of the material on precision grips, and the editors of the New Zealand
Herald for access to their files and for permission to publish figure 3 .

1 Harrison M H M, Schajowicz F, Trueta J. Osteoarthritis of the hip; study of the nature and evolution of the disease. f Bone foint Surg 1953; 35B: 598-626.

2 Goodfellow J W, Bullough P G. The pattern of ageing of the articular cartilage of the elbow joint. $\mathcal{f}$ Bone foint Surg 1967; 49B: $175-81$.

3 Bullough P, Goodfellow J, O'Connor J. The relationship between degenerative changes and load-bearing in the human hip. $₹$ Bone foint Surg 1973; 55B: 746-58.

4 Hoaglund F T, Yau A C M C, Wong W L. Osteoarthritis of the hip and other joints in Southern Chinese in Hong Kong. Incidence and

5 Alexander C J. Relationship between the utilisation profile of individual joints and their susceptibility to primary osteoarthritis. Skeletal Radiol 1989; 18: 199-205.

6 Alexander C J. Flexion angles of the knee in different resting positions and their relation to the prevalence of osteoarthritis. F Rheumatol 1991; 18: 1223-6.

7 Alexander C J, Van Puymbroeck E. Relation between the finger positions used in the precision and partial power positions used in the precision and partial power Radiol 1994. In press.

8 Sarich V. Molecular approach to human origins. In: Dolhinow P, Sarich V M, eds. Background for man. Dolhinow P, Sarich V M, eds. Background

9 Phillipson D W. African archaeology. Cambridge: Cambridge University Press, 1985: 13
10 Leakey M D, Hay R L. Pliocene footprints in the Laetoli beds at Laetoli, northern Tanzania. Nature 1979; 278: 317-23.

11 Foley R. Another unique species. Patterns in human evolutionary ecology. Harlow, Essex: Longman Scientific and Technical, 1987: 2, 177.

12 Alexander C J, Hochstein B E. Osteoarthritis of the metacarpo-phalangeal joints: the relation between ray prevalence, trauma, and utilisation. Skeletal Radiol 1993; 22: 25-31.

13 Altmann J C. Observational study of behaviour: sampling methods. Behaviour 1974; 49: 227-65.

14 Last R J. Anatomy: Regional and applied. 7th ed. Edinburgh, London: Churchill Livingstone, 1984: 71.

15 Inman V T, Saunders J B de C M, Abbott L C. Observations on the function of the shoulder joint. $\mathcal{F}$ Bone foint Surg 1944; 26A: 1-30.

16 Avis V. Brachiation: the crucial issue for man's ancestry. Southwest f Anthropol 1962; 18: 119-48.

17 Napier J R. Studies on the hands of living primates. Proc Zoo Soc Lond 1960; 134: 647-57.

8 Tuttle $R H$. The postural propulsive and prehensile capabilities in the cheiridia of chimpanzees and other great apes. In: Bourne $\mathrm{G} \mathrm{H}$, ed. The chimpanzee. Vol 2. Basel, New York: S Karger, 1970: 168-253.

19 Preuschoft H. Functional anatomy of the upper extremity. In: Bourne G H, ed. The chimpanzee. Vol 6. Basel, New York: S Karger, 1970: 34-120.

20 Dolhinow P. The living non-human primates. In: Dolhinow P, Sarich V M, eds. Background for man. Boston: Little Brown and Co., 1971: 261-84.

21 Tuttle R H. Knuckle-walking and the problem of human origins. Science 1969; 166: 953-61.

2 Washburn S L. The study of human evolution. In: Dolhinow P, Sarich V M, eds. Background for man. Boston: Little Brown and Co., 1971: 82-117.

23 Garrod A E. Concerning pads upon the finger joints and their clinical relationships. $B M \mathcal{F} 1904 ; 2: 8$.

24 Mikkelsen O A. Knuckle pads in Dupuytren's disease. Hand 1977; 9: 301-5.

25 Lovejoy C O. The origin of man. Science 1981; 211: 341-50.

26 Preuschoft H, Demes B. Biomechanics of brachiation. In: Preuschoft H, Chivers D J, Brockelman W Y, Creel N, eds. The lesser apes: Evolutionary and behavioural biology. eds. The lesser apes: Evolutionary and behavioural biology.

27 Gunn D R. Don't sit-squat. Clin Orthop 1974; 103: $104-5$

28 Solomon L, Beighton P, Lawrence J S. Rheumatic disorders in the South African negro. Part 11. Osteoarthrosis. S Afr Med F 1975; 9: 1737-40.

29 Bremner J M, Lawrence J S, Miall W E. Degenerative joint disease in a Jamaican rural population. Ann Rheum Dis 1968; 27: 326-32.

30 Mukopadhaya B, Barooah B. Osteoarthritis of the hip in Indians. An anatomical and clinical study. Indian $\mathcal{f}$ Orthrop 1967; 1: 55-62.

31 Agunwa W C R. Low incidence of osteoarthritis of the hips in contrast with osteoarthritis of the knees among rural Saudis. Why? Ann Rheum Dis 1989; 48: 351-2

32 Ota $\mathrm{H}$. Prevalence of osteoarthritis of the hip and other joints in Japanese population. $\mathcal{f}$ fpn Orthop Assoc 1979; 53: $165-80$.

33 Jurmain R. Trauma, degenerative disease, and other pathologies among the Gombe chimpanzees. Am $\mathcal{f}$ Phys Anthropol 1989; 80: 229-37.

34 Rothschild B M, Woods R J. Osteoarthritis, calcium pyrophosphate deposition disease, and osseous infection in Old World primates. Am $\mathcal{f}$ Phys Anthropol 1992; 87: 341-7.

35 Goodall J. The chimpanzees of Gombe. Patterns of behaviour. Cambridge: Harvard University Press, 1986: 236.

36 Heine J. Uber die arthritis deformans. Virchows Arch Path Anat 1926; 260: 521-663.

37 Hutton C W. Generalised osteoarthritis: An evolutionary problem. Lancet 1987; 1: 1463-5. 